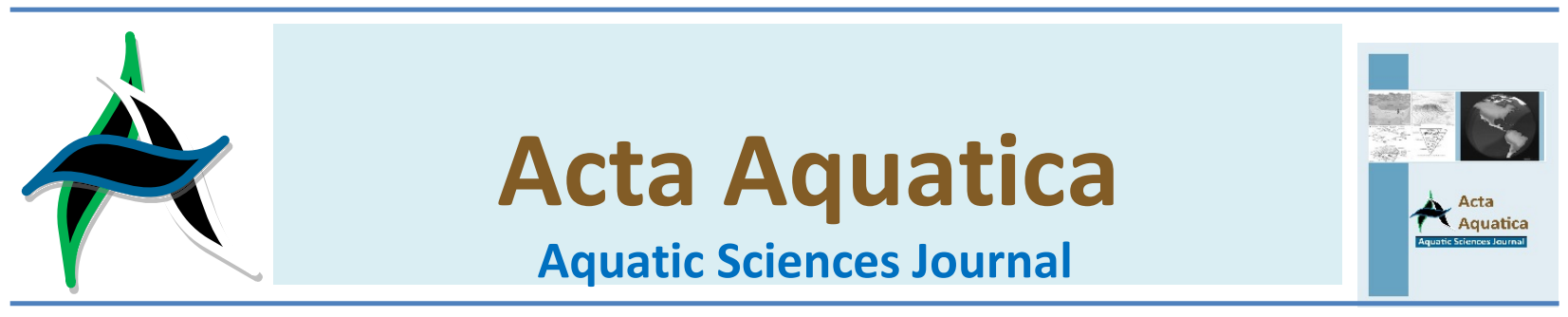

\title{
A study on the antimicrobial resistance of Lactococcus garvieae
}

\author{
Jale Korun*,1, Erbülent Altan ${ }^{1}$, Serkan Teker $^{1}$, Aycan Ulutaş ${ }^{1}$ \\ ${ }^{1}$ Department of Aquaculture, University of Akdeniz, Antalya, Turkey.
}

\begin{abstract}
The aim of this study is to determine resistance of Lactococcus garvieae isolated from sick rainbow trout (Oncorhynchus mykiss, W.) in farms in Antalya, the Mediterranean Region of Turkey to various antibiotics. Field samples studies started in July 2018 and finished in September 2018. Fish sampling studies were carried out in commercial trout farms in Kemer, Korkuteli, Serik and Manavgat districts in Antalya. Ninety fish were examined during the study period. The body weights of the fish ranged from 110 grams to 350 grams. For bacteriological studies, inoculations were prepared from the eye and internal organs of the moribund fish and inoculated onto BHIA. The inoculated petri dishes were incubated at $25 \pm 2^{\circ} \mathrm{C}$ for 72 hours. After incubation period, morphology and color of the bacterial colonies were determined. A variety of morphological, physiological and biochemical tests were applied to the isolates. The PCR technique was used in confirmation of $L$. garvieae. Antibiotic resistance tests of the isolates were performed in vitro conditions. The Multiple Antibiotic Resistance (MAR) index values of $L$. garvieae isolates were also calculated. Similar clinical findings were detected in all the affected fish. Skin color darkening, unilateral and/or bilateral exophthalmia with periocular hemorrhages, abdominal dropsy, darkening of the spleen color and splenomegaly, hemorrhages in the internal organs and ascites were detected in fish. According to the phenotypic and PCR results, the isolates were identified as Lactococcus garvieae. It was determined all of the isolates were resistant against ampicillin, nalidixic acid, nitrofurantoin, oxalinic acid and sulfamethoxazole and were susceptible to amoxicillin, enrofloxacin, florfenicol and chloramphenicol. The MAR index values of the isolates ranged from 0.3 to 0.6.
\end{abstract}

Keywords: rainbow trout, Lactococcus garvieae, antimicrobial resistance, MAR

\section{Introduction}

Lactococcosis is an important bacterial infection that seriously affects the rainbow trout culture (Kurtoğlu and Korun, 2018). The disease was first described from a trout farm in Spain in 1988. Later, it was reported from South Africa, France, Israel, Greece, Iran, Korea, Taiwan and the USA (Timur et al., 2011). The first coccal infection was detected in Turkey in 1997, and lactococcosis epizootics have been observed throughout the country since 1997 (Kurtoğlu and Korun, 2018). The development of the disease depends on the water temperature and the microbiological quality of the water; however, lactococcosis is often characterized as hyper acute haemorrhagic septicemia (Vendrell et al., 2006; Fukushima et al., 2017). Intense pathology of lactococcosis begins with rapid and general anorexia, melanosis, lethargy, loss of orientation and irregular swimming behaviour. External pathological sings of the disease are unilateral or bilateral exophthalmia, haemorrhages in the periorbital and intraocular parts of the eye, haemorrhages at the base of the fins and in the opercular region, distended abdomen, resulting from ascites and anal prolapses. Internally, infected fish show septicaemia and splenomegaly, necrosis in the spleen and kidney, bloody fluid in the intestine and can develop yellowish exudate on the

*Corresponding author: Jale Korun

Present Address: Department of Aquaculture, Faculty of Aquaculture, University of Akdeniz, Antalya, Campus, Turkey.

E-mail: jalekorun@akdeniz.edu.tr brain surface (Vendrell et al., 2006; Fukushima et al., 2017). L. garvieae is a member of the genus Lactococcus in the Streptococcaceae family (Avsever et al., 2014). The bacterium is Gram-positive, coccus shaped, facultative anaerobic and catalase negative (Rubiã and Mesquita, 2018). L. garvieae is a bacterial species which does not have host specificity. It is isolated from various fish species including rainbow trout, yellow tail, tilapia, mullet, catfish and japan eel fish. Among the cultured fish species, rainbow trout is the most susceptible to L. garvieae, while carp is the most resistant to this bacterial species (Vendrell et al., 2006; Aguado-Urda et al., 2010). Although focusing on the use of antibiotics such as erythromycin and doxycycline in the treatment of lactococcosis in general (Brunt and Austin, 2005), amoxicillin, erythromycin, oxytetracycline and low dose of doxycycline have been as common antibiotics which are used in the treatment and control of lactococcosis in rainbow trout (Vendrell et al., 2006).

The discovery and development of antimicrobial agents for the treatment of systemic bacterial infections is undoubtedly among the most exciting events in the history of microbiology (Rodgers, 2001). However, the increase in antibiotic resistance is becoming increasingly important in both human medicine and veterinary medicine. As a result, serious restrictions are imposed on the use of these agents (Rodgers, 
2001; Soltani et al., 2009). Resistance to antibiotics in bacterial species develops either by exposure to non-lethal levels of antibiotics in the environment or directly by DNA transfer mechanisms. Pathogens which show resistance against antibiotics can cause infections that are difficult to control in humans and/or animals (Lekshimi et al., 2017). Similar strategies as in other animal production sectors are used in aquaculture such as vaccination and the use of antimicrobial agents in the control of bacterial diseases (Heuver et al., 2009). The most common usages of antimicrobial agents in aquaculture are to add them to feed and to treat fish by adding the agents directly to water (dipping method). However, antimicrobial agents can be used intensely as a result of these application methods and strong selective pressure can be seen not only in fish but also in aquatic environments exposed to these agents (Heuver et al., 2009). The Multiple antibiotic resistance (MAR) index is calculated by the ratio of the number of antibiotics that the organism tested is resistant to the total number of antibiotics tested. The MAR index shows the spread of bacterial resistance in population, and the calculated MAR index reveals the presence of environmental derived bacterial strains using several antibiotics if the MAR index is greater than 0.2 (Krumperman, 1985; Ehinmidu, 2003). For this reason, it has been tried to be determined by investigating the resistance and/or susceptible of $L$. garvieae strains isolated from diseased rainbow trout (O. mykiss) against various antibiotics and the multi antibiotic resistance (MAR) in the bacterial strains with the current study.

\section{Materials and Methods}

\subsection{Sampling and isolation of bacteria}

Between June and September 2018, samples of 90 moribund rainbow trout ( $110 \mathrm{~g}$ to $350 \mathrm{~g}$ ) were taken from different commercial farms in Kemer (36 $\left.36^{\circ} 3^{\prime \prime} \mathrm{N}-30^{0} 34^{\prime} 21^{\prime \prime} \mathrm{E}\right)$, Korkuteli $\left(37^{\circ} 4^{\prime} 1^{\prime \prime} N-30^{\circ} 12^{\prime} 0^{\prime \prime} E\right)$, Serik $\left(36^{\circ} 55^{\prime} 2^{\prime \prime} N-31^{\circ} 6^{\prime} 16^{\prime \prime E}\right)$ and Manavgat $\left(36^{\circ} 46^{\prime} 59^{\prime \prime} \mathrm{N}-31^{\circ} 25^{\prime} 59^{\prime \prime} \mathrm{E}\right)$ in Antalya, the Mediterranean Region (MR) of Turkey (Fig. 1) and the samples were examined for lactococcosis. Water temperature in fish ponds was measured as the highest $21{ }^{\circ} \mathrm{C}$ and the lowest $15^{\circ} \mathrm{C}$. Ten fish from each farm were selected and necropsies of fish were performed under sterile conditions at the farm. Samples of eye, liver, spleen and kidney from fish were inoculated onto Brain Heart Infusion Agar (Merck), for bacteriological analysis. All plates were incubated at $25^{\circ} \mathrm{C} \pm 2{ }^{\circ} \mathrm{C}$ for $72 \mathrm{~h}$ (Austin and Austin, 2012). The research approval was obtained from Akdeniz University Experimental Local Ethics Committee (Number: 2018.01.015).

\subsection{Phenotypical characterization of isolates}

After the incubation period at $25^{\circ} \mathrm{C} \pm 2{ }^{\circ} \mathrm{C}$ for $72 \mathrm{~h}$, the morphology and color of the bacterial colonies on BHIA plates were examined and then subcultures of the isolates were made. A series of physiological and biochemical tests including cytochrome oxidase, catalase, O/F (Leifson) fermentation, $\mathrm{H}_{2} \mathrm{~S}$ production, growth at different temperature degrees, growth in different salt concentrations, methyl red, Voges-Proskauer $(\mathrm{VP})$, indole production, gelatinase production, citrate utilization, starch hydrolysis, $\mathrm{NO}_{2}$ production, ONPG ( $\beta$ galactosidase) and hemolysis of sheep erythrocytes were used to determine the phenotypic properties of $L$. garvieae (Vendrell et al., 2006; Sharifiyazdi et al., 2010; Austin and Austin, 2012).

\subsection{Molecular identification of L. garvieae isolates}

\subsubsection{DNA isolation}

DNA isolation from L. garvieae strains was performed in accordance with the manufacturer's recommendations using commercial DNA isolation kit. DNA samples were stored at -20 ${ }^{\circ} \mathrm{C}$ until used in PCR studies (Temizkan and Arda, 2004).

\subsubsection{Polymerase Chain Reaction (PCR)}

PCR technique was used in the confirmation of $L$. garvieae strains isolated in the study. Each assay contained 20

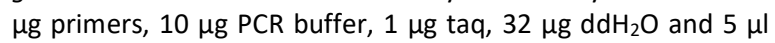
DNA template within a $50 \mu \mathrm{l}$ reaction. The further identification of the bacterium, the forward primer PLG-1 (5'CATAACAATGACAATCGC-3') and reverse primer PLG-2 (5'GCACCCTCGCGGGTTG-3') prepared by targeting the 16S rRNA gene sequence (Zlotkin et al., 1998) were synthesized and used. PCR reactions were carried out using a commercial kit and the PCR cycles were set according to Ravelo et al., (2003).

\subsubsection{Agarose gel electrophoresis}

PCR amplification products were run in $1 \%$ agarose gel for 45 minutes at $100 \mathrm{~V}$. Later, the bands were visualized on the transilmulator under UV lamp.

\subsection{Antibiotic susceptibility tests}

Antibiotic susceptibility tests of L. garvieae strains were performed in two replicates according to disc agar diffusion technique in vitro conditions (CLSI, 2006). After the turbidity of the bacterial suspension was adjusted to McFarland no: $0.5\left(1.5 \times 10^{8} \mathrm{CFU} / \mathrm{mL}\right)$, the suspension was spread onto the surface of petri dishes containing MuellerHinton (Condalab). The commercial antibiotic discs were placed on the surface of the medium. The petri dishes were incubated under aerobic conditions for 24 to $28 \mathrm{~h}$ at $28 \pm 2{ }^{\circ} \mathrm{C}$. Then, the diffusion zone diameters observed around the discs were measured at the end of the incubation period and the arithmetic averages were taken. The evaluation of the zone diameters was made according to NCCLS (2003), EUCAST (2011), CLSI (2016) and EUCAST (2019). The strains were determined as sensitive, intermediate resistance and resistance. Commercial antibiotic discs Bioanalyse in the study are given as follows: amoxicillin $(25 \mu \mathrm{g})$, ampicillin $(10 \mu \mathrm{g})$, bacitracin $(0.04 \mu \mathrm{g})$, enrofloxacin $(25 \mu \mathrm{g})$, erythromycin $(15 \mu \mathrm{g})$, florfenicol $(30 \mu \mathrm{g})$, flumequine $(30 \mu \mathrm{g})$, furazolidone $(15 \mu \mathrm{g})$, kanamycin $(30 \mu \mathrm{g})$, chloramphenicol $(30 \mu \mathrm{g})$, nalidixic acid $(30$ $\mu \mathrm{g})$, nitrofurantoin $(300 \mu \mathrm{g})$, oxytetracycline $(30 \mu \mathrm{g})$, sulfamethoxazole $(25 \mu \mathrm{g})$, streptomycin $(10 \mu \mathrm{g})$ and trimethoprim $(5 \mu \mathrm{g})$.

\subsection{Multi Antibiotic Resistance (MAR)}

The MAR index of $L$. garvieae strains isolated from moribund fish in the farms was calculated according to the formula $a / b$. A represents the number of antibiotics that the isolated bacteria show resistance, while $b$ represents the number of antibiotics that the isolate is exposed to (Krumperman, 1985).

\section{Results}

3.1. Clinical findings

3.1.1. Behavioral symptoms of the fish

Similar clinical symptoms were observed in fish affected by lactococcosis in all farms which were visited for 
sampling. The affected fish appeared lethargy and were in appetent.

\subsubsection{External clinical signs of the fish}

All affected fish showed darkening of skin, unilateral and/or bilateral exophthalmia with periocular hemorrhages, pallor of the gills, opacification in one eye (Fig. 2) and loss of the eye in some cases, eroded fins and they also had abdominal dropsy and anal prolapsed.

\subsubsection{Internal clinical signs of the fish}

Internally, clinical signs consisted of splenomegaly and darkening of the spleen (Fig. 2), hemorrhages in the liver, muscle (Fig. 2), gonads, Internal clinical sings of the fish pyloric caeca, accumulation of ascetic fluid in the intestinal and peritoneal cavity and darkening of the kidney.

\subsection{Phenotypic properties of L. garvieae strains}

\subsubsection{Morphological characterization of the strains}

Eighty-two L. garvieae strains were isolated in the present study. After incubation period for $72 \mathrm{~h}$ on BHIA, bacterial colonies were white color, circular and convex (Fig. 4) when examined in a stereo microscope. The isolates of $L$. garvieae did not exhibit active or passive movement in the wet mount preparations. The bacterial cells were Gram-positive and oval-coccus shaped under the light microscope $(x 40)$ and the cells occurred in short chains and/or single.

\subsubsection{Physiological characterization of the strains}

All 82 isolates of L. garvieae were able to develop at 4 ${ }^{\circ} \mathrm{C}, 25^{\circ} \mathrm{C}$ and $37^{\circ} \mathrm{C}$. When the salinity tolerances of the isolates were investigated, the isolates were able to develop at different salt concentrations including $0 \%, 2 \%, 4 \%$, and $6.5 \%$ $\mathrm{NaCl}$. The results are presented in Table 1.

\subsubsection{Biochemical characterization of the strains}

The all isolates were fermentative and negative for the cytochrome oxidase and catalase tests. They produced $\alpha$ (alpha)-hemolytic colonies on the blood agar. The isolates were methyl red (MR) positive but did not produce indole, $\mathrm{H}_{2} \mathrm{~S}$, amylase, gelatinase and Voges-Proskauer (VP). All biochemical traits of the isolates are presented in Table 1.

\subsection{Results of PCR study}

Further identification of 82 strains identified as $L$. garvieae according to the bacteriological study results and isolated from all fish samples was done using by PCR technique. All the strains gave $1100 \mathrm{bp}$ amplicons in the agarose gel (Fig. 5).

\subsection{Antibiotic susceptibility tests results}

According to the antimicrobial susceptibility test results of 82 L. garvieae strains isolated in the study, all strains $(100 \%)$ were found to be resistant to ampicillin, nalidixic acid, nitrofurantoin, oxolinic acid and sulfamethoxazole. All strains (100\%) were susceptible to amoxicillin, enrofloxacin, florfenicol and chloramphenicol. While 47 of the 82 strains $(57.32 \%)$ were sensitive against bacitracin, 35 strains were found to show resistance against the same antibiotic. 49 of 82 strains $(59.76 \%)$ were susceptible to erythromycin, the remaining 43 strains showed resistance. While 71 strains $(86.59 \%)$ were resistant to flumequine, 11 strains were found to be sensitive. While 61 (74.39\%) of 82 strains were sensitive to furazolidone, 21 strains were resistant, 36 strains were moderately resistant to kanamycin, 41 strains were resistant and 7 strains (8.54\%) were susceptible to the same antibiotic. 78 strains (95.12\%) were sensitive to oxytetracycline, 4 strains showed resistance. Although $75(91.46 \%)$ of 82 strains were resistant against to streptomycin, 7 strains were sensitive to the same antibiotic and 75 strains were resistant to trimethoprim while 7 strains $(8.54 \%)$ were found to be resistant against this antibiotic. The reference ranges given in Table 2 were used to determine the antibiotic susceptibilities of the strains.

\subsection{Multi Antibiotic Resistance (MAR) results}

In the study, the MAR index values of $L$. garvieae strains isolated from moribund fish in trout farms in Kemer, Korkuteli, Serik and Manavgat were found to be 0.5, 0.3, 0.6 and 0.4 , respectively. It was determined that the MAR index result was greater than 0.2 in all strains.

\section{Discussion}

\subsection{Behavioral symptoms and clinical signs of the fish}

Karami et al., (2019) isolated L. garvieae strains from sick rainbow trout samples in farms located in Kohkilooieh and Boyerahmad provinces in Iran. The researchers reported that they observed behavioral findings such as lethargy, lack of feeding, gathering in water inlets and outlets, irregular swimming in the affected fish. As clinical findings in these fish, bilateral exophthalmia and hemorrhages in the eyes, darkening in the skin color, skin ulcers in some fish, enlargement and color change in the spleen, hemorrhages in the liver and visceral fats were detected (Durmaz and Kılıçoğlu, 2015; Karami et al., 2019). Durmaz and Kılıçoğlu (2015) informed behavioral symptoms such as anorexia, lethargy and irregular swimming in the fish affected by lactococcosis in the trout farms in the Black Sea Region of Turkey. At necropsy, hemorrhages in the liver, spleen and kidneys, splenomegaly and accumulations of yellowish fluids in abdominal cavity were seen. The main clinically symptoms in this study were similar to the symptoms noticed in other works other parts of the world such as Brazil, Iran and in Turkey (Durmaz and Kilıçoğlu, 2015; Fukushima et al., 2017; Karami et al., 2019).

\subsection{Phenotypical characterization of the L. garvieae isolates}

Identification of $L$. garvieae may be done by a series of phenotypic diagnostic tests. However, some biochemical properties of the bacteria vary depending on the strain (Vendrell et al., 2006). Sharifiyazdi et al., (2010) reported that L. garvieae strains isolated from 32 rainbow trout affected in Iran by lactococcosis were non-motile, Gram-positive, coccusshaped, catalase and oxidase negative and caused alpha hemolysis in the blood agar. These 32 strains gave negative reactions for $\mathrm{H}_{2} \mathrm{~S}, \mathrm{VP}$ and indole. Timur et al., (2011) isolated and identified $L$. garvieae from rainbow trout farms which located in the Marmara Region of Turkey. It was noted that the strains were non-motile, Gram-positive and formed short chains. The bacteria were cytochrome oxidase and catalase negative and produced alpha hemolytic colonies on the blood agar. The strains gave positive reaction for MR test. The citrate reaction of the strains was negative. The authors informed that the strains were able to growth at $6.5 \% \mathrm{NaCl}$. In the present study, 82 L. garvieae strains isolated and identified from moribund fish samples. It was determined that $L$. garvieae strains formed small whitish colonies on BHIA. They were Gram-positive, oval-cocci shaped, non-motile, fermentative, cytochrome oxidase and catalase negative. These findings 
agree with those of Sharifiyazdi et al., (2010) and Timur et al., (2011).

\subsection{Results of $P C R$ identification studies}

The PCR amplification of genomic DNA from $L$. garvieae isolates using the PLG-1 and PLG-2 primers from the region of the $16 \mathrm{~S}$ rRNA defined by Zlotkin et al., (1998) produced a single amplicon product with a fragment of 1100 bp in length. Haghighi Karsidani et al., (2009) used these primers to identify cases of streptococcosis/ lactococcosis in culture rainbow trout in Iran. According to the results of the study, 37 (35.2\%) of 108 Gram-positive cocci were identified as L. garvieae. The isolates produced $1100 \mathrm{bp}$ amplification as a result of the PCR study.

\subsection{Antibiotic susceptibility tests results}

Lactococcosis is a major disease problem affecting rainbow trout culture in the Southern Europe countries such as Italy, Spain, France, Portugal, Greece and Turkey and in the Middle East (Savvidis et al., 2007; Soltani et al., 2008). Erythromycin, oxytetracycline and enrofloxacin are commonly used antibiotics in the treatment of sick fish in farms (Savvidis et al., 2007). Despite the in vitro antimicrobial test results of $L$. garvieae, the use of erythromycin, oxytetracycline and enrofloxacin for therapeutic purposes in those farms is not satisfactory (Savvidis et al., 2007). Kurtoğlu and Korun (2018) reported that $L$. garvieae strains isolated from sick fish in trout farms which were located in Fethiye, the Mediterranean Region of Turkey were susceptible to ampicillin, erythromycin, chloramphenicol, sulphametoxazole, oxytetracycline and trimethoprim. Karami et al., (2019) stated that L. garvieae strains isolated from rainbow trout in Iran were resistant against tetracycline, streptomycin and enrofloxacin; however, tetracycline and enrofloxacin have been mostly used in fish farms in the country. Fukushima et al. (2017) stated that only oxytetracycline is allowed against L. garvieae in Brazil. However, the widespread use of antibiotics is not effective in the treatment of lactococcosis due to the development and spread of antibiotic resistance (Fukushima et al., 2017; Karami et al., 2019). In this study, the high MAR index values of $L$. garvieae strains isolated from sick rainbow trout supported the resistance status in the isolates as stated above.

The resistance and sensitive patterns of the $L$. garvieae isolates in the present study were mostly similar and all were resistant against ampicillin, nalidixic acid, nitrofurantoin, oxolinic acid and sulfametoxazole, whereas all of the isolates were sensitive to amoxicillin, enrofloxacin, florfenicol and chloramphenicol. All L. garvieae isolates were highly sensitive to furazolidone and oxytetracycline. Kurtoğlu and Korun (2018) reported that L. garvieae strains isolated from sick fish in the trout farms in Fethiye (the Mediterranean Region of Turkey, MR) contained plasmids and noticed that the strains containing plasmids showed resistance against bacitracin, flumequine, furazolidone, kanamycin, nalidixic acid and streptomycin. In this study, the L. garvieae strains isolated from sick fish in fish farms located in Antalya (MR) were completely resistant against ampicillin unlike L. garvieae strains isolated from sick fish in trout farms located in Fethiye (MR). Erythromycin was mostly used in the treatment of sick fish in farms where lactococcosis was detected. In vitro antibiotic test studies, $56.76 \%$ of the strains were found to be sensitive against erythromycin. This situation revealed that $L$. garvieae was sensitive against erythromycin both in in field and laboratory conditions; however, when these results were evaluated, it was concluded that as a result of intensive use of erythromycin for control of lactococcosis in the farms conditions, it might be caused by a decrease in susceptibility to this antibiotic in the L. garvieae strains. In conclusion, the use of erythromycin in the treatment of lactococcosis may be difficult in later times and for this reason, alternative protection and control methods are needed.

\section{Acknowledgements}

This project was supported by Akdeniz University the Scientific Research Projects Coordination Unit (Project ID: FBA2018-3089 ID).

\section{References}

Aguado-Urda, M., Lopez-Campos, G. H., Fernandez-Garayzabal, J. F., Martin-Sanchez, F., Gibello, A., Dominguez, L., Blanco, M. M., 2010. Analysis of the genome content of Lactococcus garvieae by genomic interspecies microarray hybridization. BMC Microbiology, 12(79), 1-8.

Austin, B., Austin, D. A., 2012. Bacterial Fish Pathogens. Disease of farmed and Wild Fish. Springer, UK.

Avsever, M. L., Tanrıkul, T. T., Güroy, D., Metin, S., Akşit, H., 2014. Investigation of certain blood parameters in rainbow trout (Oncorhynchus mykiss Walbaum, 1792) naturally infected with Lactococcus garvieae. J FisheriesSciences.com, 8(2), 114-120.

Brunt, J., Austin, B., 2005. Use of a probiotic to control lactococcosis and streptococcosis in rainbow trout, Oncorhynchus mykiss (Walbaum). J. Fish Dis., 28, 693701.

CLSI (Clinical and Laboratory Standards Institute), 2006. Methods for antimicrobial disk susceptibility testing from aquatic animals: approved guideline CLSI. Document M42-USA.

CLSI (Clinical and Laboratory Standards Institute), 2016. Performance standards for antimicrobial susceptibility testing. CLSI Supplement M1005, USA.

Durmaz, Y., Kılıçoğlu, Y., 2015. Detection of naturally infected rainbow trouts (Oncorhynchus mykiss Walbaum, 1792) by Lactococcus garvieae with molecular methods and culture techniques and determination of antibiotic susceptibility profiles of agent in a trout farm. Atatürk Üniversitesi Vet. Bil. Derg., 10(2), 109-115 (in Turkish with English abstract).

Ehinmidu, J. O., 2003. Antibiotic susceptibility patterns of urine bacterial isolates in Zaria, Nigeria. Trop. J. Pharm. Res., 2(2), 223-228.

EUCAST (European Committee on Antimicrobial Susceptibility Testing), 2011. Breakpoints tables for interpretation of MICs and zone diameters. Europe.

EUCAST (European Committee on Antimicrobial Susceptibility Testing), 2019. Breakpoints tables for interpretation of MICs and zone diameter. Version 9.0. Europe.

Fukushima, H. C. S., Bailone, R. L., Ranzani Paiva, M. J. T., 2017. Lactococcosis in reared fish in Brazil and control strategies. J. Vaccines Vaccin., 8(3), 357-359. 
Haghighi Karsidani, S., Soltani, M., Nikbahhat Brojeni, G., Ghasemi, M., Skall, H. F., 2010. Molecular epidemiology of zoonototic streptococcosis/lactococcosis in rainbow trout (Oncorhynchus mykiss) aquaculture in Iran. Iran J. Microbiol., 12(4), 199-120.

Heuver, C. E., Kruse, H., Grave, K., Colligen, P., Karunasagar, I., Angulo, F. J., 2009. Human health consequences of use of antimicrobial agents in aquaculture. J. Food Safety, 49, 1248-1253.

Karami, E., Alishahi, M., Molayemraftar T., Ghorbanpour, M., Tabandeh, M. R., Mohammadian, T., 2019. Study of pathogenicity and severity of Lactococcus garvieae isolated from rainbow trout (Oncorhynchus mykiss) farms in Kohkilooieh and Boyerahmad province. Fisheries and Aquatic Sciences, 22(21), doi: 10.1186/s41240-019-0135-2.

Korun, J., Timur, G., Yardımcı, R. E., Balcı, B. A., 2018. A study on detecting infections caused by some coccal species on the cultured rainbow trout (Oncorhynchus mykiss, W.). Atatürk Üniversitesi Vet. Bil. Derg., 13(2), 149-158 (in Turkish with English abstract).

Krumperman, P. H., 1983. Multiple antibiotic resistance indexing of Escherichia coli to identify high-risk sources of fecal contamination of foods. Applied Environ. Microbiol., 46, 165-170.

Lekshimi, M., Parvathi, A., Kumar, S., Varela, M. F., 2017. The good production environment and development of antimicrobial resistance in human pathogens of animal origin. Microorganisms, 5.11: doi: 103390/microorganisms 5010011.

Kurtoğlu, M., Korun, J., 2018. A study on plasmid profiles and isolation of Lactococcus garvieae from the young rainbow trout (Oncorhynchus mykiss, W.). JAVST, 3(1), 11-22.

NCCLS (National Committee for Clinical Laboratory Standards), 2003. Disk Difüzyon Ek Tablolar. M100-S13 (M42), Türk Mikrobiyoloji Cemiyeti, İstanbul (in Turkish).

Ravelo, C., Magariños, B., López-Romalde, S., Toranzo, A. E., 2003. Molecular fingerprintings of fish-pathogenic Lactococcus garvieae strains by random amplified polymorphic DNA analysis. J. Clin. Microbiol., 41, 751756.
Rodgers, C. J., 2001. Resistance of Yersinia ruckeri to antimicrobial agents in vitro. Aquaculture, 196, 325345.

Rubiã, C. A., Mesquita, E. F. M., 2018. Lactococcus garvieae: emergent pathogen usually misidentified as Enterococcal species. MOJ Biol. Med., 3(2), 27-28.

Savvidis, G. K., Anatolitiotis, C., Kanaki, Z., Vafeas, G., 2007. Epizootic outbreaks of lactococcosis disease in rainbow trout, Oncorhynchus mykiss (Walbaum), culture in Greece. Bull. Eur. Ass. Fish Pathol., 27(6), 223-228.

Sharifiyazdi, H., Akhlaghi, M., Tabatabaei, M., Mostafavi Zadeh, S. M., 2010. Isolation and characterization of Lactococcus garvieae from diseased rainbow trout (Oncorhynchus mykiss, Walbaum) cultured in Iran. Iran J. Vet. Res., 11(4), 342-350.

Soltani, M., Nikbakht, Gh., Mousavi, H. A. E., Ahmadzadeh, N., 2008. Epizootic outbreaks of lactococcosis caused by Lactococcus garvieae in farmed rainbow trout (Oncorhynchus mykiss) in Iran. Bull. Eur. Ass. Fish Pathol., 28(5), 207-212.

Soltani, M., Grodratnema, M., Ahari, H., Ebrahimzadeh Mousavi, H. A., Atee, A., Dastmalchi, F., Rahmanaya, J., 2009. The inhibitory effect of silver nanoparticles on the bacterial fish pathogens, Streptococcus iniae, Lactococcus garvieae, Yersinia ruckeri and Aeromonas hydrophila. Int. J. Vet. Res., 3(2), 137-142.

Temizkan, G., Arda, N., 2004. Moleküler Biyolojide Kullanılan Yöntemler. BiYOGEM Yayın No: 2, Nobel Tıp Kitapevleri, İstanbul, 151 sayfa (in Turkish).

Timur, G., Yardımcı, R. E., Ülkü, Ç., Çanak, Ö., 2011. Diagnosis of lactococcosis by bacteriological and histopathological methods in farmed rainbow trout (Oncorhynchus mykiss, L.) at the Marmara Region. Istanbul University Journal of Fisheries \& Aquatic Sciences, 26, 63-81 (in Turkish with English abstract).

Vendrell, D., Balcázar, J. L., Ruiz-Zarzuela, I., de Blas, I., Gironées, O., Múzquiz, J. L., 2006. Lactococcus garvieae: a review. Comp. Immun. Microbiol. Infect. Dis., 29, 177-198.

Zlotkin, A., Eldar, A., Ghittino, O., Bercavier, H., 1998. Identification of Lactococcus garvieae by PCR. J. Clin. Microbiol., 36, 983-985. 


\section{Captions for figures:}

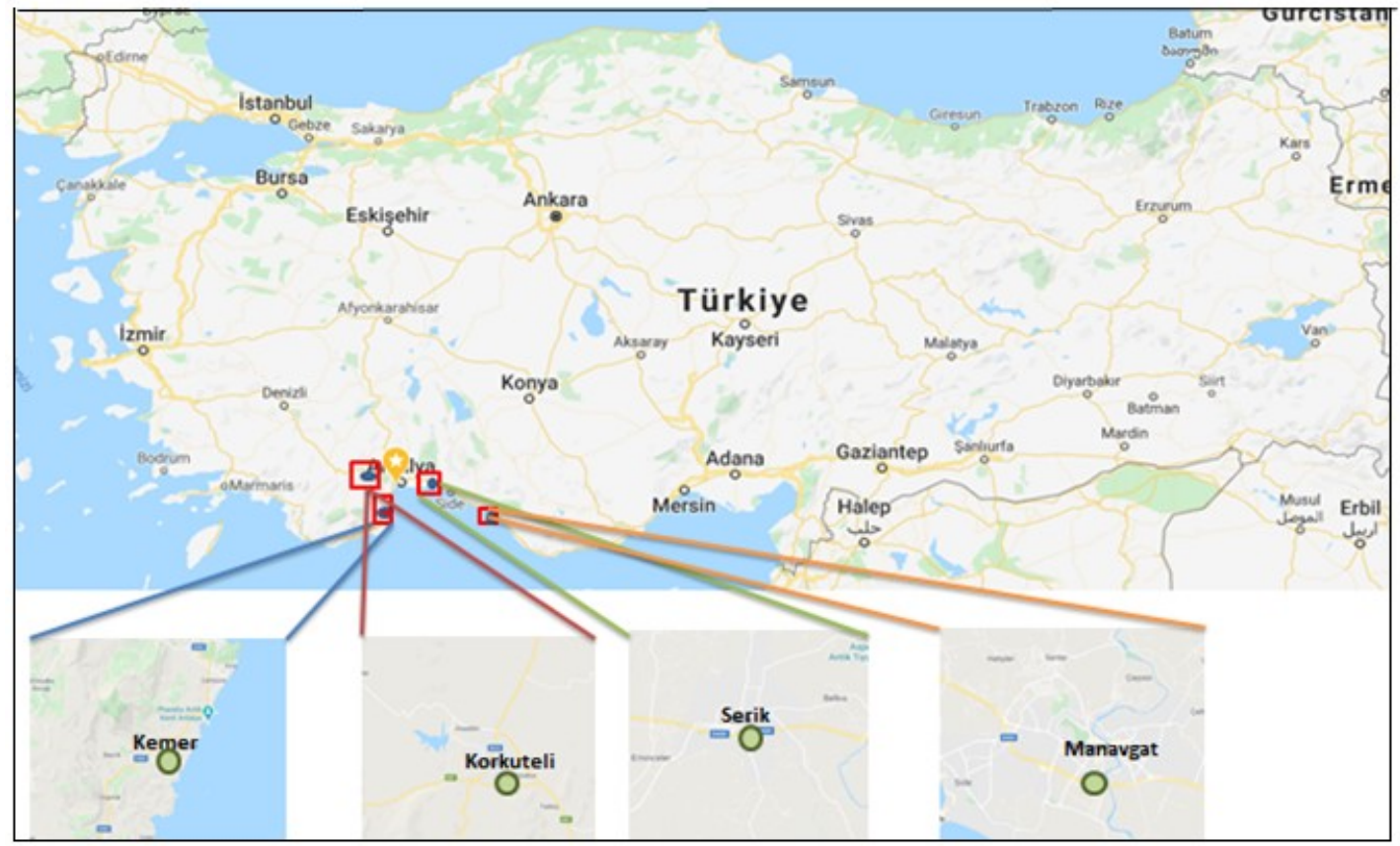

Fig. 1. Location of sampling areas in Antalya at the Mediterranean Region of Turkey (taken from google maps)

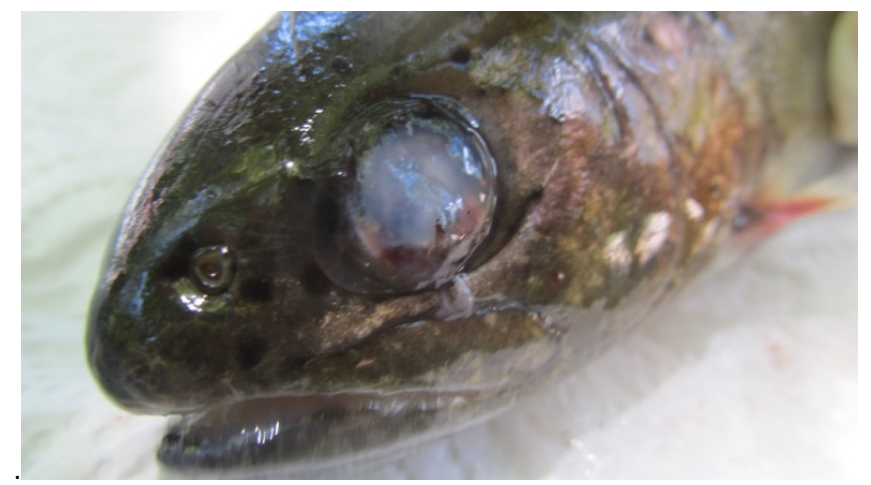

Fig. 2. Opacification in eye of the moribund fish affected by lactococcosis

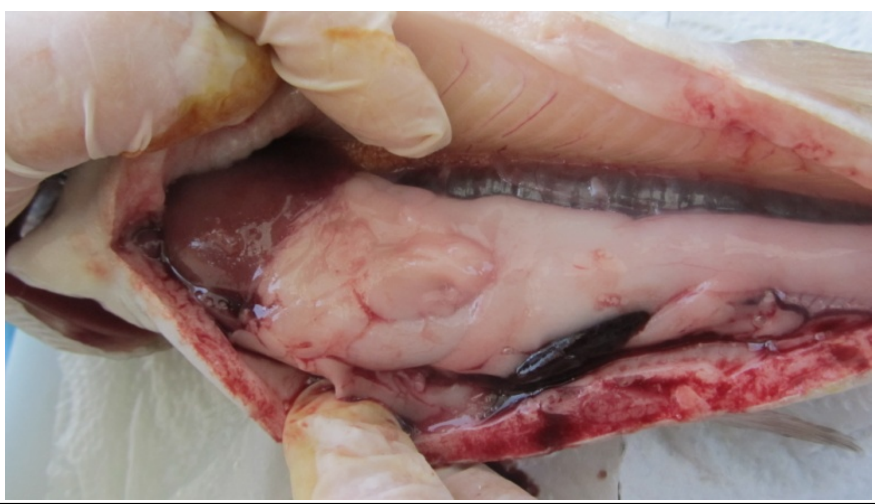

Fig. 3. Hemorrhages in the muscle pyloric caeca, splenomegaly and darkening of the spleen in the moribund fish. 


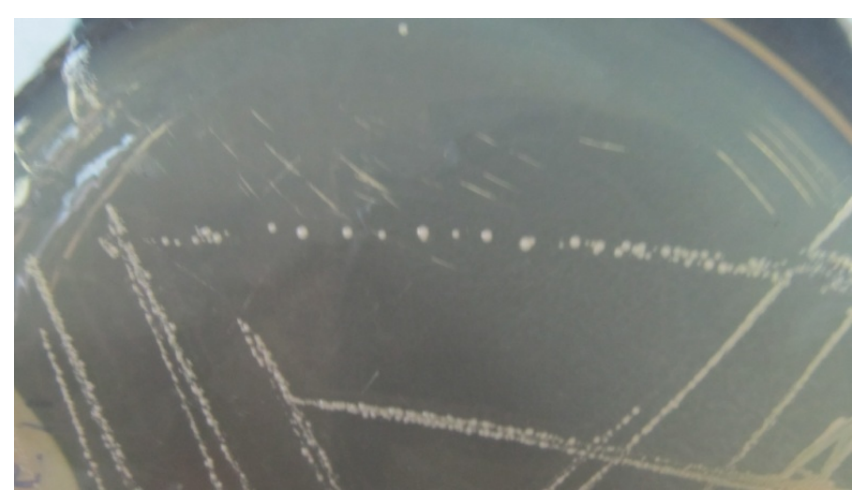

Fig. 4. Bacterial colonies of L. garvieae isolated from moribund fish

Table 1. Phenotypic characteristics of L. garvieae strains isolated from moribund rainbow trout in the study

\begin{tabular}{|c|c|c|c|c|c|}
\hline \multirow[b]{3}{*}{ Characteristics } & \multirow{2}{*}{$\begin{array}{l}\text { Kemer } \\
\text { (43 strains) }\end{array}$} & \multirow{2}{*}{$\begin{array}{l}\text { Korkuteli Serik } \\
\text { (9 strains) }\end{array}$} & \multicolumn{2}{|c|}{ Manavgat } & L. garvieae* \\
\hline & & & (10 strains) & (20 strains) & (ATCC 43921) \\
\hline & & & & & \\
\hline Gram-stain & + & + & + & + & + \\
\hline Motility - & - & - & - & - & \\
\hline Catalase - & - & - & - & - & \\
\hline Oxidase - & - & - & - & - & \\
\hline $\mathrm{O} / \mathrm{F}$ & $\mathrm{F}$ & $\mathrm{F}$ & $\mathrm{F}$ & $\mathrm{F}$ & $\mathrm{F}$ \\
\hline $\mathrm{H}_{2} \mathrm{~S}$ & - & - & - & - & - \\
\hline VP & - & - & - & - & + \\
\hline MR & + & + & + & + & + \\
\hline Hemolysis & $\alpha$ & $\alpha$ & $\alpha$ & $\alpha$ & $\alpha$ \\
\hline Citrate & - & - & - & - & - \\
\hline Indole & - & - & - & - & a \\
\hline Gelatinase & - & - & - & - & - \\
\hline Amylase - & - & - & - & - & \\
\hline ONPG & - & - & - & - & - \\
\hline McConkey & - & - & - & - & - \\
\hline \multicolumn{6}{|l|}{ Growth in: } \\
\hline $0-2 \% \mathrm{NaCl}+$ & + & + & + & + & \\
\hline $4-6.5 \% \mathrm{NaCl}$ & + & + & + & + & + \\
\hline \multicolumn{6}{|l|}{ Growth at: } \\
\hline $4{ }^{\circ} \mathrm{C}$ & + & + & + & + & - \\
\hline $25^{\circ} \mathrm{C}$ & + & + & + & + & a \\
\hline $37^{\circ} \mathrm{C}$ & + & + & + & + & + \\
\hline
\end{tabular}




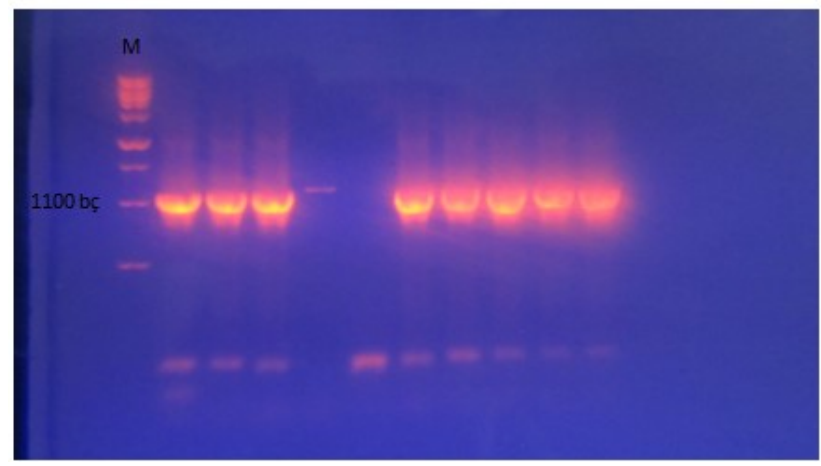

Fig. 5. Results of PCR study of $L$. garvieae strains in the agarose gel. M: Marker.

Table 2. Reference ranges used in antibiotic susceptibility detection of L. garvieae strains*

\begin{tabular}{|c|c|c|c|}
\hline \multirow[b]{2}{*}{ Ampicillin } & Resistance & \multirow{2}{*}{$\begin{array}{l}\text { Intermediate Resistance } \\
12-13\end{array}$} & Sensitive \\
\hline & $\leq 11$ & & $\geq 14$ \\
\hline Bacitracin & $<14$ & - & - \\
\hline Erythromycin & $\leq 13$ & $14-17$ & $\geq 18$ \\
\hline Florfenicol & $\leq 14$ & $15-18$ & $\geq 19$ \\
\hline Flumequine & $<15$ & $16-18$ & $>21$ \\
\hline Furazolidone & $\leq 9$ & - & - \\
\hline Kanamycin & $\leq 13$ & $14-17$ & $\geq 18$ \\
\hline Oxalinic acid & $\leq 10$ & $11-13$ & $\geq 14$ \\
\hline Oxytetracycline & $\leq 18$ & $19-22$ & $\geq 23$ \\
\hline Streptomycin & $\leq 11$ & $12-14$ & $\geq 15$ \\
\hline Trimethoprim & - & - & $20-28$ \\
\hline
\end{tabular}

*: NCCLS (2003), EUCAST (2011), CLSI (2016), EUCAST (2019) 